\title{
LA EDUCACIÓN POPULAR EN PROCESO DE CONSTRUCCIÓN DEL ESTADO COMUNAL EN VENEZUELA
}

\author{
POPULAR EDUCATION IN THE CONSTRUCTION PROCESS \\ OF THE COMMUNAL STATE IN VENEZUELA
}

\section{EDUCAÇÃO POPULAR NO PROCESSO DE CONSTRUÇÃO DO ESTADO COMUNAL NA VENEZUELA}

Samuel H. Carvajal Ruíz

Paulina E. Villasmil Socorro ${ }^{2}$

\begin{abstract}
Resumo: O objetivo desta contribuição é refletir criticamente sobre os aspectos teóricos e práticos da educação popular no contexto da construção do poder popular na Venezuela. Enquanto algumas considerações teóricas e conceituais sobre essa proposta educacional são apontadas, as contribuições dos pedagogos venezuelanos para esse movimento também são recuperadas. Finalmente, registram-se algumas experiências no desenvolvimento de sua práxis no trânsito complexo do modelo rentista-petrolífero em vigor no país, para uma sociedade democrática, participativa e dirigente como fundamentos espirituais da sociedade comunal emergente.
\end{abstract}

Palavras - chave: Educação popular - Democracia Direta - Movimentos Sociais - Movimento Popular - Poder Popular - Sociedade Comunal.

Resumen: La presente aportación tiene como propósito reflexionar críticamente sobre aspectos teórico - prácticos de la educación popular en el contexto de construcción del poder

${ }^{1}$ Doutor em Ciências da Educação pela Universidad Autónoma de Barcelona, Catalunya. Atua como Professor da Universidad Nacional "Simón Rodríguez" del Núcleo Regional de Educación Avanzada de Caracas, Venezuela, onde Coordena os Programas de Especialização em "Currículo e Gestión del Desarrollo Social"; é docente dos Seminários "Problematización de la praxis educativa y los sentidos del trabajo impartidos" no Programa de Doutorado em "Ciencias de la Educación" do Núcleo Regional de Educación Avanzada de Caracas; é integrante do Grupo de Investigación sobre Formación de Profesores del Mercosur/Cono Sur. ORCID iD: http://orcid.org/0000-0003-0747-296X.E-mail: cursosunesr2015@gmail.com

2 Doutoranda em "Ciencias para el Desarrollo Estratégico" pela Universidad Bolivariana de Venezuela (UBV); Mestre em Didática e Organização Escolar pela Universidad Complutense de Madrid. Atua como professora na Universidad Nacional Experimental "Rafael María Baralt" (UNERMB), onde também atua como investigadora em ciências da educação e em ciências sociais no Centro de Estudios Socio-Históricos y Culturales. É integrante do Grupo de Investigación sobre Formación de Profesores del Mercosur/Cono Sur. É militante do Movimiento Pedagógico Revolucionario Venezolano (MPR). ORCID iD: http://orcid.org/0000-0002-7298-741X .E-mail: paulinavillasmil@gmail.com 
popular en Venezuela. Al tiempo que se apuntan algunas consideraciones históricas, así como teórico - conceptuales sobre esta propuesta educativa, se recuperan igualmente aportes de pedagogos Nuestroamericanos a este movimiento. Finalmente, se registran algunas experiencias en desarrollo de su praxis en el complejo tránsito desde el modelo rentístico petrolero hoy vigente en el país, hacia una sociedad democrática, participativa y protagónica como fundamentos espirituales de la emergente sociedad comunal.

Palabras clave: Educación Popular - Democracia Directa - Movimientos Sociales Movimiento Popular - Poder Popular - Sociedad Comunal.

\begin{abstract}
The purpose of this contribution is to critically reflect on theoretical and practical aspects of popular education in the context of building popular power in Venezuela. While some theoretical - conceptual considerations about this educational proposal are pointed out, contributions of Venezuelan pedagogues to this movement are also recovered. Finally, some experiences in the development of his praxis in the complex transit from the rentier-oil model in force in the country, to a democratic, participatory and leading society as spiritual foundations of the emerging communal society are recorded.
\end{abstract}

Keywords: Communal State - Direct Democracy - Social Movements - Popular Education Popular Movement - Popular Power.

\title{
La educación como base del proyecto de liberación nacional
}

La historia de la emancipación americana es fecunda en experiencias y aportes educativos vinculados al proceso de liberación nacional. Resulta difícil concebir una de esas experiencias que no viniera acompañada de una teorización y puesta en escena del papel de la educación en la lucha por la independencia. Las ideas pedagógicas que tempranamente comienzan a ser preponderantes plantean la secular tensión de corte positivista entre la civilización y la barbarie.

La historia de la educación venezolana exhibe un proceso de luchas por alcanzar un sistema educativo inclusivo, que forme ciudadanos para la vida en democracia, un proceso de avances, conflictos y tensiones impulsados por las fuerzas antagónicas que datan de los propios inicios de la República. En este proceso de luchas los principios pedagógicos libertarios expuestos por Simón Rodríguez, formulados desde y para la América, en favor de una escuela pública y para todos, constituyen el músculo político e ideológico - cultural de la emancipación. De allí que en Venezuela, educación y lucha social son procesos de raíces comunes, Simón Rodríguez planteó la conquista por la libertad, más allá de la consecución del poder territorial y político, ser libres suponía transformar las "masas en pueblo" para la configuración del nuevo republicano, del actor histórico de la América libre, este cometido solo podía ser posible a través de la educación popular.

Por ello resulta imprescindible abordar en esta aportación y, aunque sea de manera escueta, considerando de manera especial el contexto en que se produce, las ideas precursoras del maestro Simón Rodríguez y de El Libertador Simón Bolívar en relación con el papel de la educación encarnada en el proyecto político de las revoluciones independentista americana.

Tal vez, es el maestro Simón Rodríguez el precursor de las ideas decoloniales en nuestra Abya Yala, pero también, de la educación popular. Cabe tan sólo recordar 
aquella sentencia que aún retumba en nuestras conciencias, que hiciera a comienzos del siglo XIX la que afirmaba: "¿Dónde iremos a buscar modelos? La América Española es original. Original han de ser sus Instituciones y su Gobierno. Y originales los medios de fundar unas y otro. O inventamos o erramos" (RODRÍGUEZ, 1990, p. 88).

Ese proyecto pedagógico que bien se puede denominarse político, resaltaba el papel de la "educación social" como instrumento para la consolidación de las repúblicas nacientes, como elemento clave en la construcción de la nueva sociedad. En este esfuerzo misionero, la escuela se constituye en fuente del saber, como factor clave en la configuración cultural de la sociedad y una palanca fundamental en el proceso de alfabetización. Como afirmaría Téllez: "Hacer escuela, en el sentido de una escuela hecha vida y hacedora de vida, lo que implicará inventar propio asociado a la construcción de las nacientes Repúblicas Americanas" (TÉLLEZ, 2019, p. 34).

Es decir, la escuela como un espacio inclusivo, para todos, que trabaja en la formación del "nuevo republicano" e instruye a las generaciones en el trabajo, en la producción y promociona los valores de las sociedades emergentes, en la construcción de las emergentes relaciones sociales.

Es en este contexto emancipador que emerge protagónico el verbo y la acción del Libertador Simón Bolívar, quien siendo pupilo del maestro Rodríguez en edades tempranas, coincide con su pensamiento cuando en el Discurso de Angostura declara que: "Las naciones marchan hacia el término de su grandeza con el mismo paso que avanza la educación."

Otro gran maestro venezolano, Luis Beltrán Prieto Figueroa (FIGUEROA PRIETO, 2006), sintetiza las ideas educativas de Bolívar, haciendo énfasis en los siguientes aspectos: a) Bolívar depositaba su confianza en la educación como fuerza transformadora de la vida humana, que incidiría en la mutación de las estructuras sociales; b) confiaba en el poder de la educación como posibilidad en la construcción y porvenir de las futuras repúblicas; c) por tanto, tenía plena certeza en la educación como posibilidad de cambio del sujeto destinatario del su influencia; y d) promovía la educación y sus virtudes como ámbito de creación y desarrollo.

En resumen, se podría afirmar, siguiendo a Iluska Salazar en este caso refiriéndose al maestro Rodríguez, pero que puede ser también síntesis del pensamiento de Bolívar, que: "el proyecto de Educación Popular, entendiéndola como educación general sustentada en lo inclusivo, en su carácter completamente público y, por ende, social" (SALAZAR, 2019, p. 52), constituye el sustento político transformador del pensamiento de los precursores de la independencia americana.

\section{Una aproximación a la relación educación, educación popular - poder popular. Reflexiones iniciales}

La educación y su práctica como expresión hegemónica de los sectores dominantes permite vehicular y perpetuar los dispositivos culturales y materiales del poder cooptado por las élites y en favor de sus intereses, en clara negación del sentido profundo de la democracia. Para la tarea cuentan con ingentes recursos e instrumentos 
dirigidos a "naturalizar" la exclusión, la opresión y el dominio generalizado de todos los ámbitos de la sociedad. Esta posición ventajosa facilita la construcción del sentido común que funciona como sedimento y nutriente de la reproducción, al punto de "naturalizar" las condiciones de opresión sobre vastos sectores sociales, cultural y materialmente excluidos; por tanto, también negados a acceder a los ámbitos de influencia y dirección.

Este asunto, el referido a los mecanismos de la reproducción cultural y material a través de la educación y del aparato escolar, ampliamente investigado y debatido a lo largo del siglo pasado y en lo que va de éste ${ }^{3}$, constituye un elemento clave en la configuración de la hegemonía cultural que se expresa en la materialización de los mecanismos de los que se vale el poder.

Leemos con Marx que: "Los hombres hacen su propia historia, pero no la hacen a su libre arbitrio, bajo circunstancias elegidas por ellos mismos, sino bajo aquellas circunstancias con que se encuentran directamente, que existen y les han sido legadas por el pasado (MARX; ENGELS, 2003, p.13).", destacando así las determinaciones histórico - culturales que rigen las relaciones sociales y las consecuencias de éstas en las relaciones de poder. Recupera el pensador alemán la pesada carga de la tradición, de las seculares formas de ejercicio del poder como mecanismo de opresión.

Desde otra perspectiva, Durkheim afirma que la educación como entidad social, es decir, como hecho social, pone al sujeto en contacto con una sociedad determinada, es decir, constituye un vehículo de cultura en el proceso de socialización. Por tanto:

\begin{abstract}
La educación es la acción ejercida por las generaciones adultas sobre aquellas que no han alcanzado todavía el grado de madurez necesario para la vida social. Tiene por objeto el suscitar y desarrollar en el niño un cierto número de estados físicos, intelectuales y morales que exigen de él tanto la sociedad política en su conjunto como el medio ambiente específico al que está especialmente destinado (DURKHEIM, 1975, p. 53)
\end{abstract}

En otras palabras, el sujeto y éste como parte de la sociedad es producto de un tiempo concreto, situado históricamente, por tanto, la educación y sus efectos sobre éste es tributaria a estas condiciones tanto materiales como inmateriales derivadas de la herencia cultural.

Lo anterior ubica al programa educativo de las élites y al conjunto de dispositivos a su servicio en el centro del debate teórico y práctico, en el que se refuerzan los correajes de control y dominio, y/o se gestan desde los intersticios del propio tejido social - comunitario las manifestaciones de resistencia e impugnación del modelo hegemónico.

De igual manera, así como alumbra los sentidos políticos de la educación, convertida en práctica legitimadora del saber y de las relaciones sociales que se reproducen en todo el tejido social, constituye al mismo tiempo en un escenario fecundo del conflicto de clases, es decir, también la escuela se convierte en territorio de disputa del poder.

\footnotetext{
3 Algunos autores que aportaron a este debate durante el siglo pasado fueron. Nikos Poutlanzas, Louis Althusser, Pierre Bourdieu, Charles Baudelot, Jacques Passeron, Paul Willis, Stephen Bowles, Tomás Vasconi, entre otros.
} 
Este hecho como fenómeno general, que contextualiza las relaciones sociales que se reproducen en un momento histórico determinado revela las tensiones sociales, políticas y culturales existentes, al tiempo que propone otras prácticas educativas que marchan a contracorriente de estos intereses y prácticas hegemónicas. Manifestaciones histórico - culturales que crean vínculos de resistencia y de organización; pequeños núcleos de poder desde fragmentos de las bases populares que exigen su organicidad.

Se trata de reconocer entonces, que los conflictos de clase tienen en el campo educativo un escenario estratégico en disputa, que las tensiones propias de la sociedad contemporánea se expresan definitivamente en el campo de la praxis educativa como uno de los espacios fundamentales del disciplinamiento de la sociedad.

Más aún, el proceso metabólico del régimen del capital como maquinaria generadora de exclusiones por tanto de desigualdades es, dialécticamente, uno de los campos en el que se gestan las condiciones para el despliegue pedagógico transformador, es decir, la contracara del relato "normalizado" en el currículo como prescripción de los determinantes culturales - educativos hegemónicos.

En este sentido, el proyecto educativo de las élites gobernado por el régimen del capital, contribuye con las formas de materialización de las dinámicas excluyentes y opresivas generadas en los pliegues de la sociedad, segmentando, coartando y cooptando las posibilidades de liberación del pueblo y el ejercicio del poder, limitando o impidiendo el acceso a instancias de decisión; al mismo tiempo que en su interior deja las simientes para gestar su propia impugnación.

Es desde las periferias sociales, en los márgenes de la sociedad formal, en los que históricamente se han venido fraguando las experiencias de educación popular. Tanto en el pasado de la mano de los proyectos emancipadores del siglo XIX, como recientemente, en el contexto de desarrollo del régimen del capital, las experiencias dirigidas a concienciar al pueblo sobre su condición de poder originario y a desplegar sus capacidades organizativas, cobran fuerza en la medida que las tensiones generadas por la exclusión en el interior de las sociedades se hacen más evidentes.

Este compromiso pedagógico con los excluidos es lo que perfila a la educación popular como opción educativa crítica y liberadora que, como afirmaba Julio Barreiro sea "un instrumento de contribución inmediata a una efectiva participación popular en procesos de transformación de la sociedad clasista y opresora" (BARREIRO, 1979, p. 26); y que encarna un proyecto de encuentro y unidad de los desheredados de la tierra, parafraseando a Fanón, que persigue: "liberarse a sí mismos y a los opresares" (FREIRE, 1994 , p. 2) como sugería el maestro Paulo Freire, se erige como herramienta cultural y de organización política de los pueblos en la construcción y formación del nuevo sujeto político.

Cuando se hace referencia a la formación del sujeto político se trata de un asunto de máxima trascendencia en el complejo trayecto de construcción del poder popular y a la educación popular como dispositivo cultural esencial en este proceso. Un asunto de primer orden es la consideración del término pueblo y su alcance político a los propósitos de la educación popular. Dussel lo identifica con la potentia, como sede del poder político (DUSSEL, 2010). 
La praxis de la educación popular se genera, materializa y contribuye en el proceso de configuración histórica de lo que Dussel denomina "Pueblo", es decir, en:

\begin{abstract}
[...] el acto colectivo que se manifiesta en la historia en los procesos de crisis de hegemonía (y por ello de legitimidad), donde las condiciones materiales de la población llegan a límites insoportables, lo que exige la emergencia de movimientos sociales que sirven de catalizador a la unidad de toda la población oprimida, la plebs, cuya unidad se va construyendo en torno a un proyecto analógico - hegemónico, que incluye progresivamente todas las reivindicaciones política, articuladas desde necesidades materiales económicas (DUSSEL, 2007, $p$. 10).
\end{abstract}

En este sentido, referirse al sujeto político es destacar aquél que se involucra en actividades políticas, es decir, que trasciende del ámbito privado al ejercicio público en defensa de los derechos colectivos, "que se asume como constructor de su propia realidad. Además, reconoce la responsabilidad que tiene frente a la necesidad de transformar la realidad" (RODRÍGUEZ; GALEANO, 2007, p. 41).

Continúa Freire acotando que "[...] la educación popular como un esfuerzo de las clases populares, un esfuerzo a favor de la movilización o un esfuerzo incluso dentro del propio proceso de movilización y organización popular con miras a la transformación de la sociedad" (FREIRE, 1985, p. 18).

En este sentido, la educación popular marca el horizonte como práctica social liberadora en procura del protagonismo consciente y organizado de los sectores populares, con la ardua tarea formativa que toma como punto de partida la cotidianidad y sus complejidades convertidas en fuente del saber y de conocimientos para favorecer los objetivos políticos de transformación de las realidades que oprimen a las mayorías.

Tal vez la clave la ofrecía el propio maestro Freire cuando afirmaba que:

\begin{abstract}
La rebeldía es el punto de partida indispensable para la deflagración de la justa ira, pero no es suficiente. La rebeldía, como denuncia, necesita prolongarse hasta una posición más radical y crítica, la revolucionaria, fundamentalmente anunciadora. La transformación del mundo implica la dialéctica entre denuncia de la inhumana situación y el anuncio de su superación, en el fondo nuestro sueño (FREITAS, 2002, p. 26). ${ }^{4}$
\end{abstract}

Otros autores aportaron aproximaciones al constructo, tales como Peresson, Cendales y Mariño, que concebían la educación popular como proceso colectivo, que aspira convertir a los sectores populares en sujeto histórico - transformador, protagonista del proyecto de liberación, que sintetice sus aspiraciones de clase (PERESSON; MARIÑO, 1983). Que persigue, según García Huidrobo, Martinic y Ortiz "que los sectores sociales tomen conciencia de la realidad fomentando la organización y la participación popular" (GARCÍA, 1989, p. 16).

Lo anterior propone forjar y/o acompañar entre todos en hacer emerger el espíritu de lucha, creatividad y organización latente en las bases populares, en un contexto donde:

Las formas de pensar y hacer la política están fundamentadas en las colectividades, la fusión de fuerzas y la capacidad organizativa y movilizadora ... Los supuestos

${ }^{4}$ En Cartas a Cristina, citado por José Cleber de Freitas, 2002, p. 26. 
políticos y los recursos organizativos que esgrimen pasan por el zaguán donde resguardan las herramientas necesarias para constitución de un movimiento social: memoria histórica, alianzas estratégicas y organización de exigencias, a fin de resituarlas en dos coordenadas que dan firmeza al mapa de la movilización y la manifestación (SALAZAR, 2013, p. 157-158).

En otras palabras, siguiendo con Dussel, el pueblo como parte del "proyecto hegemónico que asume las reivindicaciones de los diferentes movimientos sociales, que son particulares (y deben ser), deben entrar efectivamente en un proceso de diálogo y traducción" (DUSSEL, 2007, p. 10). Para lo cual, agregaríamos que, el dispositivo Educación Popular constituye un mecanismo de comunicación intra pueblo, contexto de experiencias y diálogos en la conformación de la dimensión estratégica del proyecto transformador.

La educación popular propone entre sus objetivos, entonces, las prácticas dialógicas, de conocimiento - reconocimiento para la construcción del sujeto colectivo, es decir, el "nosotros". En la medida que este "nosotros", se hace orgánico emerge el sujeto histórico convertido en pueblo luego de siglos de "silencio", es decir, convertido en poder. La organización da cuenta del segundo objetivo educación popular; la capacidad de la actuación colectiva, atendiendo a una visión estratégica. Es decir, una hegemonía con propósito transformador. Finalmente, el proceso en su totalidad revela que los cimientos de "lo anterior", su amalgama cultural se resquebraja. Es la transformación de la cultura otro de los grandes objetivos que persigue la educación popular como estrategia cultural - educativa que, dialécticamente, propone formas de resistencia y permite el reconocimiento e identidad del sujeto colectivo en y por su historia.

\section{Los andamiajes del Estado comunal}

Durante todo el período denominado como Cuarta República, el escenario político va a estar marcado por las luchas de los movimientos populares en defensa de la democracia, por un lado y, las acciones represivas de orden y control social ejercidos por el Estado interventor. Dos acontecimientos históricos se registran a finales del siglo XX que obligaron un giro en la historia política venezolana con consecuencias en las formas de organización y participación social, así como en la forma de entender y agenciar el ejercicio de la política. El primero, lo constituye la insurrección popular denominada el Caracazo ${ }^{5}$ (1989) el segundo, la emergencia de la Revolución Bolivariana.

El giro histórico desencadenado en Venezuela en los inicios del siglo XXI, supera la concepción de las antiguas fuerzas partidistas de la democracia representativa, se trata más bien, de un movimiento entendido como:

[...] Una corriente histórica emancipatoria que se define antimperialista y antineoliberal. Constituye una fuerza social, política y simbólica que articula la lucha social y la lucha política. A esta construcción colectiva se incorpora un sujeto

\footnotetext{
${ }^{5}$ El Caracazo marcó un punto de inflexión en el decurso político neoliberal en Venezuela. El desgaste de los partidos políticos provocado por los regímenes neoliberales de carácter profundamente antipopular extiende una grieta en el sistema de representatividad que no tendrá vuelta atrás. Esta crisis palmaria en 1989, abrirá el cauce para la rebelión cívico - militar del 4 de febrero de 1992.
} 
revolucionario que proviene de movimientos políticos de izquierda, cristianos de base militantes de la teología de la liberación y de la educación popular - ambos generaron movimientos pedagógicos de base robinsoniana y freiriana - grupos religiosos protestantes, movimientos feministas, comunidad LGBTIQ, ecologistas, afrodescendientes, indígenas, sindicatos de trabajadores, campesinos, artistas, maestros, intelectuales, artesanos, individualidades, cooperativistas. Este gran torrente que acompaña la gesta de la Revolución Bolivariana es a lo que luego vamos a denominar el poder popular (VILLASMIL, 2010, p. 20).

El programa puesto en marcha por la Revolución Bolivariana contiene como líneas de acción:

1. Retomar en camino de construcción de la soberanía: de lo que se trata es de poner en marcha diversos mecanismos de discusión asamblearia para redescubrir las raíces históricas nuestroamericanas y venezolanas, identificar las claves de la dependencia y trazar estrategias de lucha por la defensa del territorio de las influencias imperialistas. Estas discusiones han acompañado varios procesos constituyentes, los primeros para la aprobación en referendo de la nueva Constitución de la República Bolivariana de Venezuela y la constituyente educativa para el nuevo proyecto de Educación Bolivariana. Así mismo, vale la pena destacar la participación popular en los Congresos de la Patria, los cuales sirvieron para el análisis, en todos los sectores de la población, de los mecanismos de guerra utilizados por las fuerzas hegemónicas imperiales sobre el pueblo venezolano. Se menciona también el ejercicio del parlamentarismo de calle, como una forma de ejercicio del poder constituyente en su condición de pueblo legislador.

2. La construcción del Estado Comunal: se propone echar a andar procesos jurídicos y organizativos que superen la noción del Estado Burgués y den paso al precepto constitucional de ejercicio de la participación protagónica del pueblo organizado. En este caso, el concepto puesto en marcha es el Poder Popular y su base organizativa la conforman los Consejos Comunales, los cuales contienen los principios del modelo de participación protagónica y germen del socialismo bolivariano. Su significatividad transformadora es alimento e impulso de la defensa de lo público como condición fundamental para la salvaguarda de los derechos sociales y para vencer las asimetrías provocadas por el sistema neoliberal. Desde el Plan Nacional Simón Bolívar (2007 - 2013) se plantea el concepto de la Nueva Geometría del Poder, consistente en la transformación de la estructura social desde su base primaria organizativa y gestionaria del autogobierno.

3. Propone la superación del modelo económico capitalista depredador por un modelo de desarrollo productivo ecosocialista, valora el desarrollo endógeno y la producción social por encima del enriquecimiento privado sin límites, propio de la razón capitalista.

4. Contempla la necesaria unión geopolítica regional a través de nuevos órganos de cooperación y defensa entre países para constituir bloques de poder que garanticen el diálogo internacional en condiciones de respeto e igualdad. El punto clave de desarrollo de la corriente bolivariana es la 
consolidación del Poder Popular, no en balde, organizar su complejidad ha pasado por la promulgación de todo un cuerpo de leyes que regulen el amplio espectro del ejercicio del Poder Popular. Pero no habrá consolidación del Poder Popular bajo el modelo del Estado Liberal Burgués, ya lo decía Ernesto Che Guevara cuando expresaba la imposibilidad de construir socialismo con las armas melladas del capitalismo. De allí que uno de los retos permanentes sea el de la consolidación del Estado Comunal.

\section{Para concluir, apuntes sobre el Estado comunal}

Referirse al Estado como entidad histórico - social y política implica abordar una amplia y compleja temática sobre la cual, a los efectos de este ensayo, sólo atisbaremos a realizar algunos apuntes que tributen a los propósitos de acercarnos a una caracterización mínima del Estado comunal y al proceso de construcción. El Estado es mucho más que la visión reduccionista de Kelsen al derecho, para lo cual es suficiente la existencia de un ordenamiento jurídico vigente aplicado en un territorio determinado flujo (D'AURIA, 2008, p. 9).

Álvaro García Linera asoma una reflexión en el que describe al Estado como:

[...] una estructura de relaciones políticas territorializadas $y$, por tanto, flujos de interrelaciones y de materializaciones pasadas de esas interrelaciones referidas a la dominación y legitimación política. Esta relación-Estado siempre es un proceso histórico político en construcción, en movimiento, en flujo (GARCÍA, 2010, p. 7-8).

La tradición del Estado que hasta ahora se experimenta en nuestras realidades se asemeja al que caracterizaba críticamente Engels, cuando lo describía como:

[...] un poder situado, aparentemente, por encima de la sociedad y llamado a amortiguar el conflicto, a mantenerlo dentro de los límites del "orden". Y ese poder, que brota de la sociedad, pero que se coloca por encima de ella y que se divorcia cada vez más de ella, es el Estado (ENGELS, 2006, p. 157).

Esta caracterización se hace aún más evidente y trágica con la consolidación de un Estado encuadrado para defender los intereses y las lógicas de la dominación capitalista hasta el punto de naturalizar la dominación y sus efectos sobre la sociedad, al punto de convertirlas en costumbre.

Por tanto, el desmontaje de este andamiaje de poder y dominación implicará la profundización de los conflictos de intereses que van implícitamente en los conflictos de clase. Esta deconstrucción pasa por remover la pesada loza cultural que lo amalgama todo, cuya expresión institucional se erige como un obstáculo percibo a veces insalvable.

Un clásico en la teorización sobre el Estado como Georg Jellinek (2004) propone como elementos constitutivos de éste, los siguientes aspectos a saber: El gobierno y sus formas, el poder, las instituciones, la comunidad, las leyes y el territorio. Ellos permiten una comprensión didáctica para el análisis y caracterización de las relaciones formales que se gestan en su interior, y que son escenarios de prácticas y tensiones que reflejan las dinámicas de la sociedad de la cual es tributario. En este sentido, el Estado se 
presenta como una abstracción de la sociedad que materializa la voluntad de poder en un grupo, clase o hegemonía.

Aunque todos los elementos señalados guardan importancia para la comprensión de cómo ha venido funcionando la entidad Estado hasta la actualidad, cómo es, según se mire, concebido e incluso venerado o denostado, en el devenir histórico contemporáneo; son los sedimentos de la cultura que irriga todo el tejido social institucional del Estado que funciona como muro de contención a las formas de expresión del protagonismo popular, aunque en el plano discursivo se sirva para expresar su identificación con los intereses del pueblo.

Resulta una tarea no del todo sencilla definir un hecho social en pleno proceso de construcción, mucho más, si ese proceso ha estado impregnado de una serie de contradicciones y tensiones siempre que se ha pretendido trastocar las vetustas estructuras sociales e institucionales soportadas por el poder del capital globalizado. Este es el escenario en el que ocurre la aspiración de la construcción en Venezuela del Estado Comunal.

Vargas y Sanoja (2015), al hablar de la sociedad comunal hacen un esfuerzo epistémico, no tanto de definir el nuevo Estado que debiera gestarse para superar el modelo heredado de la razón moderna europea, sino por explicar las variables que intervienen en la conformación de la Sociedad Comunal, lo cual supone nuevas configuraciones en las relaciones sociales, en las relaciones de producción y en las relaciones de producción del poder. Este esfuerzo se hace necesario por las razones que aducen:

\footnotetext{
La cartografía del territorio nacional venezolano vigente desde mediados del siglo XIX, representa la visión territorial jerárquica capitalista del poder del Estado liberal burgués. Por ello la cartografía de la Sociedad Comunal debe expresar - por el contrario - una visión territorial que dibuje el carácter transversal y democrático del Poder Popular socialista, así como un nuevo concepto historiográfico del proceso sociocultural venezolano que sustente, explique y legitime los cambios operados gracias a la Revolución Bolivariana. Para la sociedad venezolana ello es el equivalente a poseer una nueva cultura asentada en elementos visuales del espacio nacional que incluye el espacio comunal, visión que debe imprimirse en el imaginario popular (VARGAS, 2015, p. 10).
}

Si bien la Constitución de la República Bolivariana de Venezuela (1999) no define el Estado venezolano como un Estado Comunal, sino como un Estado social, de derecho y de justicia, sí existen desarrollos conceptuales en las leyes del Poder Popular. La categoría Poder Popular enmarca una identidad colectiva con un movimiento permanente organizado de actividad social y un marco discursivo, el cual, en el despliegue de la guerra no convencional de los gobiernos estadounidenses sobre Venezuela ha constituido un muro de contención, un mecanismo de resistencia por casi dos décadas. El sujeto histórico de la corriente bolivariana ha constituido su base ideológico - cultural, a partir de los tres pilares políticos, filosóficos y de lucha social venezolana, Simón Bolívar, Simón Rodríguez y Ezequiel Zamora, legado histórico conocido como el árbol de las tres raíces.

En ello va incluido el aprendizaje sobre el significado del ejercicio de la soberanía justo en un tiempo cuando ésta, intentan diluirla a través de artilugios y relatos "globalizadores", respecto a una supuesta inexistencia de fronteras, que ciertamente la 
ejercen sólo los operadores del capital financiero, los flujos de capitales especulativos, no controlados, y el tránsito de mercancías.

El texto constitucional venezolano fundamenta la doctrina cuando establece que el pueblo es el depositario de la soberanía. Ahora bien, no es suficiente esta certeza teórica, sino que amerita corporizarse en la praxis cotidiana, en el hacer consciente de los sujetos políticos fortalecidos ética y culturalmente mediante las diversas prácticas pedagógicas políticas, por tanto, populares.

\section{Referencias}

ARIAS RODRÍGUEZ, Gina Marcela; Villota Galeano, Fabián F. De la política del sujeto al sujeto político. Ánfora, vol. 14, núm. 23, p. 39 - 52, 2007, p. 41.

Asamblea Nacional Constituyente. Constitución de la República Bolivariana de Venezuela. Caracas: Imprenta Nacional, 1999.

BARREIRO, Julio. Educación Popular y Proceso de Concientización. México: Editorial Siglo XXI, 6a edición, 1979.

D'AURIA, A. Ciencia del derecho y crítica del Estado: Kelsen y los anarquistas. Academia. Revista sobre enseñanza del Derecho. Año 6, N 12, 2008, Pp. $9-21$.

DE FREITAS, José Cleber. Revisión de las referencias teórico - prácticas. En Saúl, A.M. (Coordinadora) Paulo Freire y la formación de educadores: múltiples miradas. México, D.F.: XXI Siglo Veintiuno Editores. 2002.

DURKHEIM, Emile. Educación y sociología. Barcelona: Península, 1975.

DUSSEL, Enrique. 20 tesis políticas. Caracas: Fondo Editorial El perro y la rana, Serie Pensamiento Social, 2010.

DUSSEL, Enrique. Cinco tesis sobre el "populismo". México: UAM - Iztapalapa, 2007.

ENGELS, Federico. El origen de la familia, la propiedad privada y el Estado. Madrid: Fundación Federico Engels, 2006.

FIGUEROA PRIETO, L. B. El magisterio americano de Bolívar. Caracas: Fundación Ayacucho, 2006.

FIGUEROA PRIETO, Luis Beltrán. El magisterio americano de Bolívar. Caracas: Fundación Ayacucho, 2006.

FREIRE, Paulo. Pedagogía del oprimido. Buenos Aires: Siglo XXI, 1994.

FREIRE, Paulo. Sobre educación popular. En entrevista con Torres, R.M. México: CREFAL, 1985.

GARCÍA HUIDROBO, Juan Eduardo. Educación popular y contexto. En García Huidrobo, J.E., Martinic, S. y Ortiz, I. La educación popular en Chile. Trayectoria, experiencias y perspectivas. Santiago de Chile: CIDE, 1989.

GARCÍA LINERA, Álvaro. El Estado en transición. Bloque de podery punto de bifurcación. En García Linera, A. Et. Al. El Estado. Campo de lucha. La Paz (Bolivia): CLACSO-MUELA DEL DIABLO-COMUNA, 2010. 
JELLINEK, Georg. Teoría general del Estado. México: Fondo de Cultura Económica, 2004.

MARX, Karl. El 18 Brumario de Luis Bonaparte. Madrid: Fundación Federico Engels, 2003.

PERESSON, Mario; Mariño, Germán y Cendales, Lola. Educación popular y alfabetización en América Latina. Bogotá: Dimensión Educativa, 1983.

RODRÍGUEZ, SIMÓN. Sociedades Americanas. Caracas: Biblioteca Ayacucho, 1990.

SALAZAR, ILUSKA. Simón Rodríguez y la lucha antiimperialista de Nuestra América. En Téllez, M., Gamboa, N. y Agudelo, O (Editoras). Simón Rodríguez; resonancias de su vida y obra en nuestros tiempos. Caracas: Universidad Nacional Experimental "Simón Rodríguez", p. 51 - 63, 2019.

SALAZAR, Robinson. La construcción del nuevo sujeto político en América Latina. Estrategia para buscar la emancipación desde lo popular en el siglo XXI. Espiral, Estudios sobre Estado y Sociedad. Vol. XX, No. 57. Mayo/agosto de 2013, p. $153-173$. TÉLLEZ, MAGALDI. Notas para la descolonización en la universidad, escuchando al maestro Simón Rodríguez. En Téllez, M., Gamboa, N. y Agudelo, O (Editoras). Simón Rodríguez; resonancias de su vida y obra en nuestros tiempos. Caracas: Universidad Nacional Experimental "Simón Rodríguez", p. 33 - 46, 2019.

VARGAS ARENAS, Iraida y Sanoja Obediente Mario. La larga marcha hacia la sociedad comunal. Tesis sobre el Socialismo Bolivariano. Caracas: Fundación Editorial El Perro y La Rana, 2015.

VILLASMIL, PAULINA. El movimiento bolivariano como corriente histórica emancipadora. En Faleiro, W., Et. Al. (Coordinadores). Educação no campo e projeto histórico: conhecimento, prática e intervenção social. Goiânia: Editora Kelps, 2019.

$\begin{array}{ll}\text { Submetido em: } & \text { 20-11-2019 } \\ \text { Aceito em: } & 27-12-2019\end{array}$

